\title{
Cardiopulmonary resuscitation knowledge and skills of registered nurses in Botswana
}

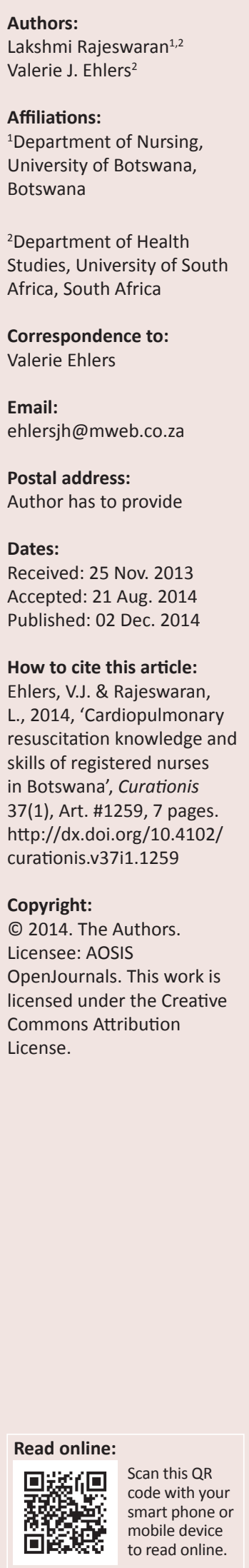

Background: In Botswana nurses provide most health care in the primary, secondary and tertiary level clinics and hospitals. Trauma and medical emergencies are on the increase, and nurses should have cardiopulmonary resuscitation (CPR) knowledge and skills in order to be able to implement effective interventions in cardiac arrest situations.

Objective: The objective of this descriptive study was to assess registered nurses' CPR knowledge and skills.

Method: A pre-test, intervention and re-test time-series research design was adopted, and data were collected from 102 nurses from the 2 referral hospitals in Botswana. A multiplechoice questionnaire and checklist were used to collect data.

Results: All nurses failed the pre-test. Their knowledge and skills improved after training, but deteriorated over the three months until the post-test was conducted.

Conclusion: The significantly low levels of registered nurses' CPR skills in Botswana should be addressed by instituting country-wide CPR training and regular refresher courses.

\section{Introduction \\ Problem statement}

Cardiopulmonary resuscitation (CPR) is a critical component of basic life support (BLS) as the first-line response to cardiac arrest before defibrillation and advanced life support become available. Whilst CPR has become well established in the healthcare systems of developed countries, it remains a developing procedure in some African countries.

Healthcare professionals' CPR knowledge and skills differ even in developed countries (Einspruch et al. 2007:74; Hopstock 2008:16). Many studies on CPR conducted in developed countries such as the United States of America (USA) (Dane et al. 2000:83), the United Kingdom (UK) (Broomfield 1996:1016), Finland (Hopstock 2008:16) and Ireland (Madden 2006:218) revealed inadequate levels of CPR knowledge and skills amongst registered nurses. However, these aspects remain unexplored in Botswana. Cardiac emergencies and road traffic accidents are on the increase in Botswana and patients' lives might depend on nurses' CPR knowledge and skills. The prognosis of in-hospital cardiac emergencies depends on delays in commencing $\mathrm{CPR}$, the available equipment and the health professionals' CPR competence (Dane et al. 2000:83).

The incidence of cardiovascular disease is likely to rise as the life expectancy for people living with HIV and/or AIDS increases due to antiretroviral therapy (ART). This is the case because antiretroviral drugs (ARVs) increase the risk of atherosclerosis and coronary artery disease including cardiac arrests (DAD study, Moller et al. 2003:1993). A study involving 20 000 patients from 20 countries showed a $26 \%$ increase in heart attacks amongst ART patients (Moller et al. 2003:1179). Botswana has an estimated $300000 \mathrm{HIV}$-infected persons aged 15-49 years, and 95\% of those received ARVs (World Health Organization 2013). In Botswana 1\% of adult mortalities are attributed to road traffic accidents and $4 \%$ to atherosclerotic disease (ischaemic heart disease and cerebrovascular accidents combined) (Republic of Botswana 2011). As nurses are usually the first professional persons to provide BLS during emergency situations, they should possess the knowledge and skills to be able to perform CPR effectively and thus to save lives.

\section{Aim of the study}

This study attempted to evaluate registered nurses' levels of CPR knowledge and skills in Botswana. 


\section{Basic life support training}

$\mathrm{CPR}$ is a developing procedure in most African countries. In hospitals nurses usually discover cardiac arrests and initiate CPR procedures. Inadequate initial assessment, inappropriate treatment and inadequate monitoring contribute to poor CPR outcomes (Nolan et al. 2001:106; English et al. 2004:53). However, there is no established cost-effective BLS training programme (Kandasami, Inbasegaran \& Lim 2003; Jat et al. 2004:58; Khan \& Rubin 2003:181).

In Botswana nurses provide up to $80 \%$ of healthcare services in primary and secondary healthcare facilities. Nurses in Botswana should thus be competent and skilled CPR providers to enhance the survival rates of cardiac arrest patients (Meaney et al. 2012: 489).

In Botswana there is no established CPR training for hospitalbased healthcare providers, and this situation is similar to that in other countries like Nepal (Roshana, Batajoo \& Piryani 2012:141), Iran (Hossein et al. 2013:51), and Kenya (Kipsang \& Bruce 2011:103).

Favourable CPR outcomes can be expected if nurses provide effective CPR interventions and have adequate resources to do so. Botswana's Ministry of Health does not provide a BLS programme throughout the country to ensure that registered nurses are knowledgeable and skilled CPR providers.

\section{Literature review}

CPR competency is defined as having the cognitive knowledge and psychomotor skills that are necessary for the effective performance of CPR in cardiac arrest situations (Broomfield 1996:1016).

A limited amount of literature exists about CPR in Africa and Botswana. Studies conducted in Australia (Hammond et al. 2000:99), Japan (Nagashima et al. 2003:427), the UK (Davies \& Gould 2000:400) and Ireland (Madden 2006:218), reveal that CPR knowledge and skills were lacking amongst nurses in these developed countries. The same trend was observed in countries like Bahrain (Marzooq \& Lyneham 2009: 294), South Africa (Govender et al. 2010:294) and Greece (Passali et al. 2011:365).

A systematic review on resuscitation training in developing countries highlighted that cognitive knowledge was higher amongst physicians than amongst nurses or students (Meaney et al. 2010:1462). Acquiring and retaining psychomotor skills vary widely if not updated on a regular basis. The complex CPR tasks require that all critical skills should be applied effectively during CPR interventions to enhance patient outcomes (Woollard et al. 2006:237).

Nurses' CPR performance varies according to their knowledge and skills, the availability of resources and regular training. A challenge for providing effective CPR interventions concerns the retention of CPR knowledge and skills (Misko \& Molle 2003:292). Factors like motivation, attitudes (Dwyer \& Williams 2002:85), leadership and teamwork (Marsch et al. 2004:51), and resuscitation experiences influence the performance and retention of CPR skills.

Nurses working in different areas reportedly demonstrated varying levels of CPR competence, and these skills deteriorated over time (Alspach 2005:8). Nurses performing CPR in accident and emergency units in real-life situations on a daily basis retained these skills better than nurses working in other departments. CPR training should be provided every 3-6 months to prevent deterioration of CPR skills and knowledge (Edgren \& Adamson 2009:e79; Hamilton 2005:288).

\section{Research method and design}

A quasi-experimental time-series design was adopted to investigate registered nurses' CPR knowledge and skills. A pre-test, intervention, post-test, and re-test after three months were utilised to determine the same registered nurses' CPR knowledge and skills.

\section{Research setting}

The study was conducted in Botswana's two referral hospitals. These hospitals were chosen because they are Botswana's only hospitals equipped with specialised professional services, including intensive care units (ICUs) and emergency care services

\section{Research population and sample}

The target population comprised all 370 registered nurses working in the 2 selected hospitals. Non-probability convenience sampling was utilised to select 102 participants from ICUs, accident and emergency (A\&E) units, medical units and surgical units. During the pre-test, training and post-test immediately after training 102 registered nurses participated, but only 70 were available during the re-test phase 3 months after completing the CPR training. Registered nurses residing in Botswana and working for at least one year in one of the selected units of the 2 participating hospitals could participate in the study. Registered nurses who had clinical experience of less than one year and/or who had participated in CPR training during the previous 2 years were excluded from the study.

\section{Data collection}

The questionnaire requested information about the participants' demographic characteristics such as age, gender, professional status, academic qualifications and formal CPR training.

During the pre-test phase each registered nurse's CPR skills were assessed for three minutes. Thereafter the nurses completed multiple-choice tests assessing their CPR knowledge. The first author, a certified BLS instructor, 
TABLE 1: Demographic and professional characteristics of registered nurses in two referral hospitals in Botswana $(N=102)$.

\begin{tabular}{|c|c|c|c|}
\hline Variables & Demographic characteristic & Frequency & Percentage \\
\hline \multirow[t]{2}{*}{ Gender } & Male & 14 & 13.7 \\
\hline & Female & 88 & 86.3 \\
\hline \multirow[t]{6}{*}{ Age group } & $21-25$ & 11 & 10.8 \\
\hline & $26-30$ & 44 & 43.1 \\
\hline & $31-35$ & 26 & 25.5 \\
\hline & $36-40$ & 11 & 10.8 \\
\hline & $41-45$ & 6 & 5.9 \\
\hline & 46 and above & 4 & 3.9 \\
\hline \multirow[t]{3}{*}{ Education } & Diploma in Nursing & 72 & 69.6 \\
\hline & $\begin{array}{l}\text { Diploma in Nursing and } \\
\text { Midwifery }\end{array}$ & 11 & 11.2 \\
\hline & Degree in Nursing & 19 & 19.2 \\
\hline \multirow[t]{6}{*}{ Work experience } & Less than 2 years & 27 & 26.5 \\
\hline & $2-3$ years & 17 & 16.7 \\
\hline & $4-5$ years & 12 & 11.8 \\
\hline & $6-7$ years & 10 & 9.8 \\
\hline & $8-9$ years & 32 & 31.4 \\
\hline & 10 or more & 10 & 3.8 \\
\hline \multirow[t]{2}{*}{ Formal CPR training } & Yes & 49 & 48.0 \\
\hline & No & 53 & 52.0 \\
\hline \multirow{5}{*}{$\begin{array}{l}\text { Frequency of CPR } \\
\text { performed }\end{array}$} & Annual & 16 & 15.7 \\
\hline & Monthly & 23 & 22.5 \\
\hline & Weekly & 26 & 25.5 \\
\hline & Daily & 8 & 7.8 \\
\hline & Never & 29 & 28.4 \\
\hline
\end{tabular}

provided a four-hour BLS training session based on the American Heart Association (AHA)'s guidelines (AHA 2005:112). CPR knowledge and skills of the participants were assessed immediately after the training and a re-test was conducted three months later to evaluate the retention of their CPR knowledge and skills.

The Little Anne CPR training mannikin, simulating the features of an average adult's physiology and anatomy, designed especially for BLS training, was used to assess registered nurses' CPR skills, as indicated in Table 1.

\section{Research instruments}

CPR knowledge was assessed by means of a 21-item multiple-choice questionnaire. The pass mark for this questionnaire was $85 \%$, as recommended by the Basic Life Support for health care providers document of the Resuscitation Council of Southern Africa (RCSA) (2005:2) and by the AHA (2005:112) because no standardised guidelines existed in the two referral hospitals of Botswana.

A 19-point skills test, similar to the approach of Berden et al. (1992:21), was used to assess the nurses' CPR skills (Berden et al. 1992:21). A maximum penalty mark of 5 or 10 or 20 was set for each question, based on that approach. Two CPRqualified evaluators assessed each participant's performance independently and the marks were consolidated. The same method was adopted during the pre-test $(n=102)$, the posttest $(n=102)$ conducted immediately after the CPR training, and the re-test $(n=70)$ conducted three months after this training.
The content validity of the instrument was enhanced by following the guidelines of CPR specified by the AHA and by the RCSA. The instrument was also evaluated by two nurse researchers, two critical care clinical specialists and a statistician. The instrument was pre-tested on 10 registered nurses who did not participate in the actual study. During the pre-testing phase the 10 participants encountered difficulties in understanding four of the 21 questions. These questions were reformulated with the assistance of a critical care nurse. The instrument was easy to score and the two independent evaluators awarded penalty points in similar ways during the pre-test phase.

The 18 steps in skills assessment were graded and penalty points assigned, based on the participants' levels of performance (see Table 1). The 19th step assessed whether the 18 steps were done in the correct sequence. The penalty points for all 19 tests added up to 240 .

\section{Data analysis}

Data were analysed using the Statistical Package for Social Sciences (SPSS) Version 15.0 program. The non-parametric test examined changes that occurred between the pre-test and post-test measures, and a $p$-value $<0.05$ was considered to be statistically significant.

\section{Results}

Out of 102 respondents, $86.3 \%(n=88)$ were females and $13.7 \%(n=14)$ were males. Most respondents were between 23 and 40 years old, and they had 2 to 10 years' experience. As many as $52.0 \%(n=53)$ of the respondents had no formal CPR training and $70.0 \%(n=71)$ had received no CPR training after completion of their basic training. Some respondents $(25.5 \% ; n=26)$ performed CPR on a weekly basis, whilst others $(22.5 \% ; n=23)$ did so monthly. As many as $40.2 \%(n=41)$ of the respondents said that patients had died during or after CPR interventions.

\section{Pre-test, post-test and re-test scores: Cardiopulmonary resuscitation knowledge}

The pre-test mean score achieved by participants in the tests that assessed their average CPR knowledge was $55.09 \%$, compared to the pass standard of $85 \%$ set by the RCSA (2005:2) and the AHA (2005:112).

Although the participants' scores increased after the training session, the post-training mean score of $80.63 \%$ was still below the expected international pass standard of $85 \%$. The mean score achieved by the participants three months after their CPR training had decreased to $70.75 \%$, indicating that the nurses' CPR knowledge had deteriorated significantly.

\section{Pre-test, post-test and re-test scores: Cardiopulmonary resuscitation skills}

The pre-test mean score achieved by participants in the tests that assessed their CPR skills indicated that only $10.33 \%$ managed to obtain a penalty score below 20 . 
Considerable improvements occurred immediately after training in the post-test $(76.55 \%)$. However, the retention level of participants had dropped by nearly $10 \%$ three months after the post-test $(66.82 \%)$.

\section{Statistical significance of cardiopulmonary resuscitation knowledge and skills tests}

Major deviations in performance amongst respondents occurred in the pre-test $(\mathrm{SD}=11.5)$, the post-test $(\mathrm{SD}=7.2)$ and the re-test three months after CPR training $(\mathrm{SD}=10.9)$ (Table 2).
The results of the CPR skills tests showed lower scores than the results of the CPR knowledge tests. The mean score of the nurses' CPR skills before training was $9.42 \%$ ( $\mathrm{SD}=9.8)$, indicating a low level of competence. Immediately following training, the post-test mean score increased to $78.31 \%(\mathrm{SD}=17.5)$, but it decreased again to $67.82 \%(\mathrm{SD}=20.2)($ Table 3$)$ in the post-test three months after CPR training.

All nurses performed poorly during the CPR skills pretest, and no one passed this test. The requisite skills, such

TABLE 2: Practical test - cardiopulmonary resuscitation skills, one rescuer.

\begin{tabular}{|c|c|c|c|}
\hline Variable & Skill component & Value & Penalty points \\
\hline \multirow[t]{2}{*}{ Variable 1} & Checking for hazards & Correct & 0 \\
\hline & & Incorrect /not performed & 5 \\
\hline \multirow[t]{2}{*}{ Variable 2} & Checking for responsiveness & Correct & 0 \\
\hline & & Incorrect /not performed & 5 \\
\hline \multirow[t]{2}{*}{ Variable 3} & Calling for help & Correct & 0 \\
\hline & & Not performed & 20 \\
\hline \multirow[t]{3}{*}{ Variable 4} & Open airway: & Correct & 0 \\
\hline & Head tilt, Chin lift & Incorrect & 10 \\
\hline & & Not performed & 20 \\
\hline \multirow[t]{3}{*}{ Variable 5} & Checking for breathing: & Correct & 0 \\
\hline & Look, listen and feel for 10 seconds & Incorrect & 5 \\
\hline & & Not performed & 10 \\
\hline \multirow[t]{3}{*}{ Variable 6} & Give two slow breaths & Correct & 0 \\
\hline & & Incorrect & 10 \\
\hline & & Not performed & 20 \\
\hline \multirow[t]{3}{*}{ Variable 7} & Ventilation volume & Correct $-76 \%$ and over & 0 \\
\hline & & Incorrect $-51 \%-75 \%$ & 10 \\
\hline & & Incorrect - below $50 \%$ & 20 \\
\hline \multirow[t]{3}{*}{ Variable 8} & Initial pulse check & Correct & 0 \\
\hline & & Incorrect & 5 \\
\hline & & Not performed & 10 \\
\hline \multirow[t]{3}{*}{ Variable 9} & Correct hand position & Correct $-76 \%$ and over & 0 \\
\hline & & Incorrect $-51 \%-75 \%$ & 10 \\
\hline & & Incorrect - below $50 \%$ & 20 \\
\hline \multirow[t]{2}{*}{ Variable 10} & Perform 30 compressions & Correct & 0 \\
\hline & & Incorrect & 5 \\
\hline \multirow[t]{3}{*}{ Variable 11} & Depth of compressions & Correct $-76 \%$ and over & 0 \\
\hline & & Incorrect $-51 \%-75 \%$ & 10 \\
\hline & & Incorrect - below $50 \%$ & 20 \\
\hline \multirow[t]{3}{*}{ Variable 12} & Release of chest compressions & Correct $-76 \%$ and over & 0 \\
\hline & & Incorrect $-51 \%-75 \%$ & 10 \\
\hline & & Incorrect - below $50 \%$ & 20 \\
\hline \multirow[t]{3}{*}{ Variable 13} & Rate of chest compressions & Correct 80-100 & 0 \\
\hline & & Incorrect $120-140$ & 10 \\
\hline & & Or $60-80$ & 20 \\
\hline \multirow[t]{2}{*}{ Variable 14} & Give two slow continuing breaths & Correct & 0 \\
\hline & & Incorrect & 5 \\
\hline \multirow[t]{2}{*}{ Variable 15} & Compression to breathing ratio $30: 2$ & Correct & 0 \\
\hline & & Incorrect & 5 \\
\hline \multirow[t]{2}{*}{ Variable 16} & Perform four complete cycles & Correct & 0 \\
\hline & & Incorrect & 5 \\
\hline \multirow[t]{2}{*}{ Variable 17} & Pulse check & Correct & 0 \\
\hline & & Incorrect & 5 \\
\hline \multirow[t]{2}{*}{ Variable 18} & Continuing CPR & Correct & 0 \\
\hline & & Incorrect & 5 \\
\hline \multirow[t]{3}{*}{ Variable 19} & Correct sequence & Correct $18-18$ steps & 0 \\
\hline & & Correct $12-15$ steps & 10 \\
\hline & & Correct 11 and below & 20 \\
\hline
\end{tabular}


TABLE 3: Registered nurses' cardiopulmonary resuscitation knowledge.

\begin{tabular}{|c|c|c|c|c|c|c|}
\hline Knowledge & $N$ & Basis & Minimum & Maximum & Mean & Standard deviation \\
\hline \multirow[t]{2}{*}{ Pre-test } & 102 & Score & 16.0 & 90.0 & 56.2 & - \\
\hline & & $\%$ & 15.9 & 88.2 & 55.0 & 11.5 \\
\hline \multirow[t]{2}{*}{ Post-test } & 102 & Score & 13.0 & 100.0 & 82.2 & - \\
\hline & & $\%$ & 13.0 & 98.4 & 80.6 & 7.2 \\
\hline \multirow[t]{2}{*}{ Re-test } & 70 & Score & 14.0 & 67.0 & 50.0 & - \\
\hline & & $\%$ & 20.0 & 95.7 & 70.7 & 10.9 \\
\hline
\end{tabular}

as giving two slow breaths, the ventilation volume, the correct hand position and the appropriate rate of chest compressions were all poorly performed. The respondents were expected to score 0 penalty points for $85 \%$ of the skills tests, but no respondent scored 0 penalty points in any of the skills tests during the pre-test. Only 39.2\% (40 out of 102) of the respondents scored 0 penalty points in the post-test immediately after the CPR training, but they still failed to meet the expected level of CPR performance of $85 \%$. In the re-test 3 months after their CPR training, only 17.1\% (12 out of 70) of respondents scored 0 penalty points, indicating deterioration of skills. Mean scores remained in the range of 9-12 in the pre-test, 72-79 in the post-test immediately after training and 62-69 in the re-test 3 months after their CPR training, irrespective of the age, gender and experience of the participants.

\section{Ethical considerations}

Permission to collect data was granted by Botswana's Ministry of Health and both hospitals' research committees, and by the Research and Ethics Committee of the Department of Health Studies of the University of South Africa.

A covering letter was attached to each questionnaire, explaining the details of the study. Participation was voluntary and informed written consent was provided by each participant. The right to decline or to withdraw from the study at any stage without incurring any penalty was explained. All data were coded and kept locked up, accessible only to the researchers and the statistician.

\section{Discussion}

Competent and knowledgeable nurses can implement effective CPR interventions to save patients' lives. This study's findings emphasise the importance of increasing the CPR knowledge and skills of Botswana's nurses, as no one passed the CPR pre-test and only a few passed the re-test three months after their CPR training.

This study produced no significant differences in terms of gender, age and experience, although a study conducted in Belgium demonstrated that accumulated work experience was associated with improved CPR skills (Verplancke et al. 2008:75).

\section{Cardiopulmonary resuscitation knowledge}

The pre-test knowledge of the registered nurses indicated that they did not know the correct compression/ventilation ratio, the compression rate, when to commence chest
TABLE 4: Registered nurses' cardiopulmonary resuscitation skills.

\begin{tabular}{lccccc}
\hline Tests on Skills & $\boldsymbol{N}$ & Minimum & Maximum & Mean & Standard deviation \\
\hline Skills \% in pre-test & 102 & .00 & 47.92 & 9.42 & 9.82 \\
Skills \% in post-test & 102 & .00 & 100.00 & 78.31 & 17.52 \\
Skills \% in re-test & 70 & 25.00 & 100.00 & 67.82 & 20.17 \\
\hline
\end{tabular}

compressions and when to assess the pulse. These are critical aspects for initiating effective $\mathrm{CPR}$, as incorrect performance of these reduces the patient's chances of survival after a cardiac arrest (Smith, Gilcreast \& Pierce 2008:59; Young \& King 2000:7).

These findings indicate that it is imperative for nurses to receive regular, periodic in-service $C P R$ courses, updating nurses on the latest CPR techniques, technologies and developments. The ability of registered nurses to perform BLS and to maintain their CPR skills and knowledge are indispensable professional requirements of all registered nurses working in healthcare settings (Hamilton 2005).

\section{Cardiopulmonary resuscitation skills}

Registered nurses' CPR skills were poor during the pretest, as no one passed (Table 4). This is consistent with findings reported in Ireland (Madden 2006:218) and Bahrain (Marzooq \& Lyneham 2009:294). The CPR skills which no registered nurse performed correctly during the current study included opening of the airway, assessing ventilation volume, initial pulse check, correct positioning and placement of the hand during $C P R$, the required number of compressions per minute, and the correct rate of compressions.

Whilst the CPR skills of the nurses improved by $67.8 \%$ after their CPR training, these skills deteriorated significantly during the 12 weeks after the CPR training. Similar findings were reported by studies reported in Ireland (Madden 2006:218) and Belgium (Regge et al. 2008:283).

All nurses should attend mandatory in-service CPR training to prevent life-threatening deterioration in their CPR skills (Leary \& Abella 2008:1). Teaching of the relevant, frequently used CPR skills could increase the survival rate of cardiac arrest victims (Oermann, Edgren \& Maryon 2011:447).

\section{Limitations of the study}

The research was confined to two referral hospitals in Botswana. This limits the inferences that could be made about other populations of registered nurses in Botswana. 
There was a high drop-out rate of participants between the initial pre-test and the post-test phase three months after the re-test. As many as $31.2 \%(n=32)$ of the registered nurses had left the services of these two hospitals when the re-test was done three months after the BLS training. These differences might have affected the accuracy of the findings.

The study was conducted using mannikins that may not provide the participants with the same competence as a reallife situation would provide.

\section{Recommendations}

CPR training in developing countries could be challenged by unavailable resources. Healthcare providers in developing countries might implement CPR interventions without regular formal training. Formal BLS and ACLS training as well as regular in-service training and recertification of BLS competency might help the registered nurses to retain their CPR knowledge and skills.

Longitudinal follow-up studies of nurses who participated in the current study could indicate critical points at which CPR knowledge and skills deteriorate. This might help to determine the optimal frequency with which CPR training should be implemented in Botswana.

\section{Conclusion}

Registered nurses working in Botswana's two participating hospitals had inadequate CPR knowledge and skills, which could impact negatively on patients' survival rates during cardiac arrest situations. Unless effective CPR training is instituted and sustained throughout Botswana, it appears unlikely that the death rate of patients suffering from cardiac emergencies will decrease.

\section{Acknowledgements}

We express our gratitude to the institutions that granted permission for data collection. We thank all registered nurses who sacrificed their time and energy to participate in the study.

\section{Competing interests}

The authors declare that they have no financial or personal relationship(s) that may have inappropriately influenced them in writing this article.

\section{Authors' contributions}

L.R. (University of Botswana and University of South Africa) identified the need for conducting this study for her D.Litt et Phil. degree. V.J.E. (University of South Africa) was a supervisor of the study and was actively involved with L.R. in all phases of the study: proposal writing, obtaining ethical clearance, designing the research instruments, interpreting the findings and writing the report. L.R. collected the data and analysed the data with the assistance of a statistician.

\section{References}

Alspach, G., 2005, 'CPR - the vanishing competency', Critical Care Nurse 25(6), 8-12.

American Heart Association, 2005, 'Guidelines for cardiopulmonary resuscitation and emergency cardiovascular care', Circulation 112-IV-206-IC211.

Berden, HJ., Pijils, N.H., Williems, F.F., Hendrick., J.M. \& Crul, J.F., 1992, 'Scoring systems for basic cardiac life support skills in training situations', Resuscitation 23(1), 21-31. http://dx.doi.org/10.1016/0300-9572(92)90159-A

Broomfield, R., 1996, 'A quasi experimental research to investigate the retention of basic cardiopulmonary resuscitation skills and knowledge by qualified nurses following a course in professional development', Journal of Advanced Nursing 28(5), 1016-1023.

Dane, T.C., Lindergren, K.S., Parish, D.C., Durham, M.D. \& Brown, T.D., 2000, 'Inhospital resuscitation: Association between ACLS training and survival to discharge', Resuscitation 47(1), 83-87. http://dx.doi.org/10.1016/S0300$9572(00) 00210-0$

Davies, N. \& Gould, D., 2000, 'Updating cardiopulmonary resuscitation skills: A study to examine the efficacy of self-instruction on nurses' competence', Journal of Clinical Nursing 9(3), 400-410. http://dx.doi.org/10.1046/j.13652702.2000.00389.x

Dwyer, T. \& Williams, L.M., 2002, 'Nurses' behaviour regarding CPR and the theories of reasoned action and planned behaviour', Resuscitation 52(1), 85-90. http:// dx.doi.org/10.1016/S0300-9572(01)00445-2

Edgren, K.S. \& Adamson, K.A., 2009, 'BSN medical-surgical student ability to perform CPR in simulation: Recommendations and implications', Clinical simulation in Nursing 5(2), e79-e83. http://dx.doi.org/10.1016/j.ecns.2009.01.006

Einspruch, E.L., Lynch, B., Aufderheide, T.P., Nichol, G. \& Becker, L., 2007, 'Retention of CPR skills in a traditional AHA heart saver course versus 30-min video self-training: A randomized study', Resuscitation 74(3), 476-486. http://dx.doi.org/10.1016/j. resuscitation.2007.01.030

English, M., Esamai, T., Wasunna, A., Were, F., Ogutu, B., Wamae, A., Snow, R.W. \& Peshu, N., 2004, 'Assessment of inpatient paediatric care in first referral leve hospitals in 13 districts in Kenya', The Lancet 363(9425), 1948-1953. http://dx.doi. org/10.1016/S0140-6736(04)16408-8

Govender, K., Rangiah, C., Ross, A. \& Campbell, L., 2010, 'Retention of knowledge of and skills in cardiopulmonary resuscitation among healthcare providers after training', South African Family Practice 52(5), 459-462. http://dx.doi.org/10.108 0/20786204.2010.10874025

Hamilton, R., 2005, 'Nurses' knowledge and skill retention following cardiopulmonary resuscitation training: a review of the literature', Journal of Advanced Nursing 51(3), 288-297. http://dx.doi.org/10.1111/j.1365-2648.2005.03491.x

Hammond, F., Saba, M., Smiles, T. \& Cross, R., 2000, 'Advanced Life Support: The retention of registered nurses' knowledge 18 months after initial training', Australian Critical Care 13(3), 99-104. http://dx.doi.org/10.1016/S10367314(00)70632-1

Hopstock, L.A., 2008, 'Cardiopulmonary resuscitation: Use, training and self confidence in skills. A self reported study among hospital personnel', Scandinavian Journal of Trauma, Resuscitation and Emergency Medicine 16(1), 16-18. http:// dx.doi.org/10.1186/1757-7241-16-18

Hossein, N.H., Afzalimoghaddam, M., Hoseinidavarani N.H. \& Hossein-Nejad Nedal, H., 2013, 'The validity of cardiopulmonary resuscitation skills in the emergency department using video-assisted surveillance: An Iranian experience', Acta Medica Iranica 51(6), 394-398.

Jat, A.A., Khan, M.R., Zafar, H., Raja, A.J., Hoda, O., Rehman, R., Lakdawala, R.H. \& Bashir, S., 2004, 'Peer review audit of trauma deaths in a developing country', Asian Journal of Surgeons 27(1), 58-64. http://dx.doi.org/10.1016/S1015 9584(09)60247-5

Kandasami, P., Inbasegaran, K. \& Lim, W.I., 2003, 'Perioperative death in Malaysia: The transition phase from a developing nation to a developed one', Medical Journal of Malaysia 58(3), 413-419.

Khan, A.N. \& Rubin, D.H., 2003, 'International paediatric emergency care: Establishment of a new speciality in a developing country', Paediatric Emergency Care 9(3), 181-184. http://dx.doi.org/10.1097/01.pec.0000081244.98249.27

Kipsang, J. \& Bruce, J.C., 2011, 'A comparison of cardiopulmonary resuscitation between two groups of advanced practice student nurses at a medical training college in Kenya', Africa Journal of Nursing and Midwifery 13(2), 103-118.

Leary, M. \& Abella, B.S., 2008, 'The challenges of CPR quality improvement in the real world', Resuscitation 77(1), 1-3. http://dx.doi.org/10.1016/j. resuscitation.2008.02.005

Madden, C., 2006, 'Undergraduate nursing students' acquisition and retention of CPR knowledge and skills', Nurse Education Today 28(1), 218-227. http://dx.doi. org/10.1016/j.nedt.2005.10.003

Marsch, C.U., Muller, C., Marquardt, K., Conard, G., Tschan, F. \& Hunziker, P.R., 2004 'Human factors affecting the quality of cardiopulmonary resuscitation in simulated cardiac arrests', Resuscitation 60(1), 51-56. http://dx.doi.org/10.1016/j. resuscitation.2003.08.004

Marzooq, H. \& Lyneham, J., 2009, 'Cardiopulmonary resuscitation knowledge among nurses working in Bahrain', International Journal of Nursing Practice 15(4), 294-302. http://dx.doi.org/10.1111/j.1440-172X.2009.01752.x

Meaney, A.P., Sutton, R.M., Tsima, B., Steenhoff, A.P., Shilkofski, N., Boulet, J.R Davis, A., Kestler, A.M., Church, K.K., Niles, D.E., Irving, S.Y. Mazhani, L. \& Nadkarni, 2012, 'Training hospital providers in basic CPR skills in Botswana: Acquisition, retention and impact of novel training techniques', Resuscitation 83(12), 1484-1490. http://dx.doi.org/10.1016/j.resuscitation.2012.04.014 
Meaney, A.P., Topjian, A.A., Chandler, K.H., Botha, M., Soar, J., Berg, R.A. \& Nadkarni, V.M., 2010, 'Resuscitation training in developing countries. A systematic review', Resuscitation 81(1), 1462-1472. http://dx.doi.org/10.1016/j. systematic review', Resuscita
resuscitation.2010.06.024

Misko, L. \& Molle, E., 2003, 'Beyond the classroom: Teaching staff to manage cardiac arrest situations', Journal for Nurses in Staff Development 19(6), 292-296. http:// dx.doi.org/10.1097/00124645-200311000-00006

Moller, F., Weber, R., Reiss, P., Thiebault, R., Kirk, O., Monforte, A., Pradier, C., Morfeldt, L., Mateu, L., Law, M., Sadr, W., De Wit, S., Sabin, C.A., Phillips, A.N. \& Lundgren, J.D., 2003, 'Cardiovascular disease risk factors in HIV patients - association with antiretroviral therapy, results from the DAD study', AIDS 358(17), 1179-1193. http://dx.doi.org/10.1097/00002030-200305230-00010

Nagashima, K., Takahata, O., Fujimoto, K., Suzuki, A. \& Iwasaki, H., 2003, 'Investigation on nurses' knowledge of and experience in cardiopulmonary resuscitation and on nurses' knowledge of the guidelines for cardiopulmonary resuscitation and emergency cardiovascular care established in 2000 - Results of a survey at Asahikawa Medical College Hospital Report', Japanese Journal of Anaesthesiology 52(4), 427-430.

Nolan, T., Angos, P., Cunha, A.J., Muhe, L., Qazi, S., Simoes, E.A., Tamburlini, G., Weber, M. \& Pierce, N.F., 2001, 'Quality of hospital care for seriously ill children in less developed countries', The Lancet 2001, 357, 106-110. http://dx.doi.org/10.1016/ S0140-6736(00)03542-X

Oermann, M.H., Edgren, S.E. \& Maryon, T., 2011, 'Effects of monthly practice on nursing students' CPR psychomotor skill performance', Resuscitation 82(4), 447-453. http://dx.doi.org/10.1016/j.resuscitation.2010.11.022

Passali, C., Pantazopoulos, I., Dontas, I., Patsaki, A., Barouxis, D., Troupis, G. \& Xanthos, T., 2011, 'Evaluation of nurses' and doctors' knowledge of basic and advanced life support resuscitation guidelines', Nurse Education in Practice 11(6), 365-369. http://dx.doi.org/10.1016/j.nepr.2011.03.010
Regge, M.D., Calle, P.A., Paepe, P. \& Monsieurs, K.G., 2008, 'Basic life support refreshers training of nurses' individual training and group training are refreshers training of nurses individual training and group training are equally effective, Resuscita
resuscitation.2008.06.015

Resuscitation Council of Southern Africa, 2005, Basic Life Support for healthcare providers, viewed 10 July 2009, from www.resuscitationcouncil.co.za/ providers, view
BLScourses/ALG

Roshana, S., Batajoo, K.H. \& Piryani, R.M., 2012, 'Basic life support: Knowledge and attitudes of medical/paramedical professionals', World Journal of Emergency Medicine 3(2), 141-145. http://dx.doi.org/10.5847/wjem.j.is sn.1920-8642.2012.02.011

Smith, K., Gilcreast, D. \& Pierce, K., 2008, 'Evaluation of staff's retention of ACLS and BLS skills', Resuscitation 78(1), 59-65. http://dx.doi.org/10.1016/j. resuscitation.2008.02.007

Verplancke, T., Peaepe, P.D., Calle, P.A., Regge, M.D., Maele, G. \& Monseiurs, K.G., 2008, 'Determinants of the quality of basic life support by hospital nurses', Resuscitation 77(1), 75-80. http://dx.doi.org/10.1016/j.resuscitation.2007.10.006

Woollard, M., Whitfield, R., Newcombe, R.G., Colquhoun, M., Vetter, N. \& Chamberlain 2006, 'Optimal refresher training intervals for AED and CPR skills: A randomised controlled trial', Resuscitation 71(2), 237-247. http://dx.doi.org/10.1016/j. resuscitation.2006.04.005

World Health Organization, 2013, Global updates on HIV treatment 2013, results, impact and opportunities 2013, viewed 02 October 2013, from www.who.int/iris/ bitstream/10665/85326 eng.pdf

Young, R. \& King, L., 2000, 'An evaluation of knowledge and skill retention following an in-house advanced life support course', Nursing in Critical Care 5(1), 7-14. 